\title{
A quantitative methodology to detect surface antigens on red blood cells using optical cell- detachment technique
}

\section{CHIH-LANG LIN ( $\square$ cllin101943@ctust.edu.tw )}

Central Taiwan University of Science and Technology

\section{SHYANG-GUANG WANG}

Central Taiwan University of Science and Technology

MENG-TSUNG TIEN

HomeRun BioTech Inc.

\section{CHUNG-HAN CHIANG}

Central Taiwan University of Science and Technology

YI-CHIEH LEE

Central Taiwan University of Science and Technology

\section{PATRICE L. BALDECK}

ENS Lyon, Laboratory of Chemistry

CHOW-SHING SHIN

National Taiwan University

\section{Research Article}

Keywords: surface antigen expression, cell-detachment, blood subtyping, whole-cell, optical tweezers

Posted Date: December 29th, 2020

DOl: https://doi.org/10.21203/rs.3.rs-134189/v1

License: (9) (i) This work is licensed under a Creative Commons Attribution 4.0 International License. Read Full License 


\section{Abstract}

The quantitative analysis of surface antigens on cells, especially red blood cells (RBCs), has attracted increasing attention due to the recognition of antigenic changes that can facilitate early diagnoses. This paper presents an alternative methodology developed using the optical cell-detachment technique to evaluate antibody-antigen interactions and quantitatively analyze the RBC surface antigen expression. RBC subtyping was used to verify the proposed detection principle based on a comparison of the bonding strengths between individual RBCs and antibody coatings. The bonding strengths were measured with serial antibody dilutions with gradually decreasing laser powers, for which a single cell was optically detached from the corresponding antibody-coated surface. With the quantitatively analysis, the proposed alternative methodology was verified as a highly sensitive technique for detecting antigen expression on the RBC surface.

\section{Introduction}

Numerous antigens are present on the cell surface, which are important molecular markers of cell functions and lineages [1], and antigenic change in quantity is critical, especially for hematologic development, immune response, and tumor progression [2-4]. For instance, the human leukocyte antigens (or CD antigens) expressed on immune cells participate in or perform functions in the immune response [5]. Many reports have shown that blood group antigen expression is correlated with tumor progression [6-8]. Also, RBCs can be classified into A, B, and $O$ groups based on inherited differences in cell surface antigens [9]. Conventionally, $A B O$ types are recognized by agglutination test but this method is not sensitive enough to reliably discriminate RBC subtypes. Rare blood type discrepancies occur when there are few $A$ and $B$ antigens on the RBC surface [10], as they form small RBC aggregates in agglutination assays that are difficult to differentiate from the 0 type.

Flow cytometry and enzyme-linked immunosorbent assays (ELISA) have been developed for the quantitative analysis of cell surface antigens. For instance, the flow cytometric analysis results performed by Cho et al. reveals that the transfect expressed $35.5 \%$ of the total $B$ antigen produced on the B101 allele transfect [11]. Chen et al. showed that the percentage of B antigen expression for the cells of B3 is $40.92 \%$ of B1 [12]. However, these methods remain limitations due to the need for large clinical samples and low sensitivity $[13,14]$. For example, flow cytometry requires more than 5,000 to 10,000 copies of the target antigen on one cell to ensure quantitative analysis [13], whereas 50,000 cells per well are needed for ELISA to obtain high optical density values and low background noise during detection [15]. More recently, the focus is shifted to the individual cell analysis to minimize sample, enhance sensitivity, and reducing analysis time. Subsequently, the optical tweezers and atomic force microscope (AFM) have been widely employed to the single-molecule biophysics research [16-21]. Optical tweezers, in contrast to AFM, are useful for single cell manipulation with precise force measurement [16]. The exerted force of optical tweezers results from the laser interaction with dielectric micro-objects, with optical force ranges in the pico-Newton to nano-Newton scales. In 1989, direct trapping of RBCs using optical tweezers was reported in the pioneering works of Ashkin et al. [22]. Subsequently, optical tweezers are now being 
used in the investigation of an increasing number of biochemical and biophysical processes [23-32]. Moreover, many easy-to-use commercial products of optical tweezers have been promoted.

In this study, we extended our preliminary works [33-35] based on the bonding of specific antigenprotein/antibody interactions and optical manipulations to develop an alternative methodology to analyze antigen expression on the whole RBC. Antigen expression was quantitatively estimated using the optical detachment technique to systematically measure serial bond strengths between a single RBC and corresponding antibody-coated slides. Herein, the optical tweezers were employed as a biosensor to measure the bonding strength of antibody-antigen interaction to analyze the expression of antigens on the whole RBC surface.

\section{Materials And Methods}

\subsection{Preparation of RBCs and antibody coatings}

Standardized RBCs were provided by Formosa Biomedical Technology Corp. (Taipei, Taiwan) and diluted 800 fold with PBS before the addition of $0.1 \mathrm{~g} / \mathrm{ml}$ BSA to prevent the RBCs sticking together and block non-specific interactions with antibodies or the slide. One drop $(\sim 0.01 \mathrm{ml})$ of the RBCs solution was incubated on the antibody-coated slides for 20 minutes at room temperature just prior the measurement. B3, the most common B subtype in the Asian population, was used as the subject of subtype identification [11].

The antibody-coated slides were prepared by protein adhesion on surfaces coated with poly-L-lysine [36,37], an efficient method to prepare antibody microarrays [38]. Cover slides (Paul Marienfeld GmbH \& Co. $\mathrm{KG} /$ Germany) were cleaned with acidic alcohol $(1 \% \mathrm{HCl}$ in $70 \%$ ethanol), rinsed thoroughly in ultrapure $\mathrm{H}_{2} \mathrm{O}$, incubated at room temperature in a 1:10 poly-L-lysine solution (Sigma-Aldrich \#P8920) for 5 minutes, then dried in a $60^{\circ} \mathrm{C}$ oven for 1 hour. Solutions of anti-A and anti-B monoclonal antibodies (1 $\mathrm{mg} / \mathrm{mL}$ ) were provided by Thermo Fisher Scientific Inc. (Waltham, USA) and diluted with PBS solutions (Sigma-Aldrich \#P4417). Poly-L-lysine coated slides were incubated in antibody solutions at room temperature for 1 hour, then for 5 minutes in $0.05 \mathrm{~g} / \mathrm{ml} \mathrm{BSA}$ solution to block non-specificity and stored at $4^{\circ} \mathrm{C}$.

\subsection{Optical tweezers for RBC manipulation}

The schematic of the optical tweezers system based on an inverted microscope platform (Olympus IX51) is shown in Fig 1. A continuous-wave Nd-YAG laser (Onset Electro-Optics, model \# ISF064-1000P) at $\lambda=1064 \mathrm{~nm}$ focalized by a high NA (1.3) microscope objective/oil (UPLFLN100XO2, Olympus) provides the trapping beam with minimum and maximum available powers of $4 \mathrm{~mW}$ and $250 \mathrm{~mW}$, respectively. Herein, the laser powers were measured at the microscope objective. During measurements, the RBCs solutions are confined to an isolated sample chamber comprising two cover slides ( $170 \mu \mathrm{m}$ thickness), and a double-faced tape (120 $\mu \mathrm{m}$ thickness) to eliminate flow disturbance. The chamber can be moved with an XYZ-axis nanopositioner (Physics Instrument, NanoCube®P611), while the laser is focused at a 
fixed position in the chamber. The optical dragging speed is kept low $(5 \mu \mathrm{m} / \mathrm{sec})$ for the static test during measurement, so the solution viscous effect can be ignored.

The basic principle of optical tweezers to produce optical forces for manipulating micron-sized dielectric objects have been described previously [39-42]. A laser beam is focused by a high numerical aperture (NA) of the microscope objective to a spot $(0.5-1.0 \mu \mathrm{m})$ in the micro-object, generating an optical trap to grasp micro-objects. For a suspended microsphere, the optical force exerted at the center mainly depends on the sphere size, the indices of medium and object, the NA of the microscope objective, and the laser power. In the cell-detachment experiment, the optical trapping spot is exerted at the edge of the attached RBC during detaching, with the size of the spot being very small compared to the RBC (about 6-8 $\mu \mathrm{m}$ ). It is assumed that the optical tweezers exerts a consistent volume, meaning the geometry differences in RBCs can be ignored. Besides, the indices of the RBC and the prepared medium and NA are consistent, so the force is linearly proportional to the laser power and the applied power $(P)$ can be used to evaluate the bonding strength $(F)$ between the RBC and antibody-coated surface, i.e. .

\subsection{Optical RBC-detachment}

First, the experiments of negative controls were performed, i.e. the cases of non-specific antibody-antigen interactions, such as 0 type RBCs or A-type RBCs on the anti-B coating, and 0 type RBCs or B-type RBCs on the anti-A coating, as shown in Fig 2. When the optical tweezers focuses on the RBC on the surface, it is vertically aligned by the torque force exerted on its disk-like geometry (Fig. 2b). The suspended RBC can be freely dragged by the optical tweezers in solution (Fig. 2c) even at very low power (i.e. $4 \mathrm{~mW}$ ). Fig. $2 \mathrm{~d}$ shows the RBC manipulation films. When the RBC antigens interact with antibodies coated on the slide, the RBC attaches to the surface (Fig. 3a). For example, Fig. 3b represents an A-type RBC attached to the anti-A-coated (non-dilution) surface, then stretched by the optical tweezers but not detached from the slide surface even at the maximum available power $(250 \mathrm{~mW})$. The RBC is deformed during pulling by optical tweezers. The basic specific interactions of antibody-antigen were verified by optical detaching with the maximum power $250 \mathrm{~mW}$ of blood types $\mathrm{A}, \mathrm{B}$, and $\mathrm{O}$ on cover slides coated with the associated anti-A and anti-B antibodies (Table 1). Each detaching test was performed on at least 5 cells 10 times, that is, 50 continuous trials and the results verified the basic specific and non-specific binding of the RBC to the corresponding antibody-coated slide.

\section{Table 1. The basic specific interactions of antibody-antigen using optical tweezers ( $250 \mathrm{~mW})$}

\begin{tabular}{ccc} 
RBC types & Anti-A surface Anti-B surface \\
\hline A & $\square$ & $\square$ \\
B & $\square$ & $\square$ \\
O & $\square$ & $\square$
\end{tabular}

$\square: R B C$ attached; $\square:$ RBC detached 


\subsection{Antibody dilution method}

The strength of the RBC antigen interaction with the coated surface is proportional to the antigenantibody associations, which depend on the antibody concentration on the functional slide surface, as well as the antigen concentration on the RBC surface. The antibody dilution method was used to quantify the RBC-antibody affinity. Serial slides coated with decreasing antibody concentrations were prepared and stored at $4^{\circ} \mathrm{C}$ before the detaching tests. The dilution fold increases by an exponent of 2 , but will be adjusted according to the test requests. For example, the dilution fold increases by 512 after 2048, such as $2560,3072,3584 . . . e t c$. The RBC-antibody affinity was quantified by the highest dilution at which the RBCs could not be detached by the optical tweezers from the antibody coating. The steps are clarified in Fig. 4).

\section{Results And Discussion}

\subsection{Agglutination tests with the dilution method}

The agglutination test with the dilution method was performed for comparing to the celldetachment method illustrated later. The antibody solutions and the blood samples (B, and B3) were prepared as described previously and the blood samples were dropped into the corresponding antibody solutions. The dilution of antibody solution was gradually increased until the non-agglutinative phenomenon was observed and the results are shown in Table 2 .

Table 2. Serial antibody dilutions using the agglutination method

Fold dilution of associated antibodies B-type RBC in B3-type RBC in anti-B solution anti-B solution

\begin{tabular}{ccc}
\hline 1 & $\square$ & $\square$ \\
2 & $\square$ & $\square$ \\
4 & $\square$ & $\square$ \\
\hline 6 & $\square$ & $\square$ \\
8 & $\square$ & $\square$ \\
\hline 16 & $\square$ & $\square$ \\
32 & $\square$ & $\square$ \\
64 & $\square$ & $\square$ \\
\hline 128 & $\square$ & $\square$ \\
\hline 256 & $\square$ & $\square$ \\
\hline 512 & $\square$ & $\square$
\end{tabular}

प: agglutinative; $\square$ : non-agglutinative 


\subsection{Optically detachment tests with the dilution method}

Serial dilutions of antibodies were used to evaluate the bonding strengths, as the bonding strength depends on the antibody concentration (Table 3). The results indicated that the interaction of the anti-B antibody with B-type RBC can still be quantified when the antibody is diluted 4096 -fold. The sensitivity was 16 -times higher than the agglutination method (256 dilution fold in Table 1). The maximum dilution for B3-type (2048) shows an apparent difference with B-type (4096), verifying precise blood subtyping without ambiguity.

Table 3. Serial antibody dilution for optical detaching tests using maximum laser power $(250 \mathrm{~mW})^{c}$ Fold dilution of associated antibodies B-type RBC on B3-type RBC on anti-B surface

\begin{tabular}{ccc} 
& anti-B surface & \\
\hline 1 & $\square$ & $\square$ \\
2 & $\square$ & $\square$ \\
4 & $\square$ & $\square$ \\
\hline 8 & $\square$ & $\square$ \\
16 & $\square$ & $\square$ \\
32 & $\square$ & $\square$ \\
64 & $\square$ & $\square$ \\
\hline 128 & $\square$ & $\square$ \\
256 & $\square$ & $\square$ \\
\hline 512 & $\square$ & $\square$ \\
\hline 1024 & $\square$ & $\square$ \\
\hline 2048 & $\square$ & $\square$ \\
\hline 2560 & $\square$ & $\square$ \\
\hline 3072 & $\square$ & $\square$ \\
\hline 3584 & $\square$ & $\square$ \\
\hline 4096 & $\square$ & $\square$ \\
\hline 5120 & $\square$ & $\square$ \\
\hline
\end{tabular}

प: RBC attaches; $\square: R B C$ detached

Subsequently, the bonding verifications were performed using laser powers gradually decreased by 5 $\mathrm{mW}$ for further dilutions until the RBCs could be easily detached by the optical tweezers using the lowest available laser power $(4 \mathrm{~mW})$. The results listed in Table 4 indicate that the interaction of the B-type RBCs vs anti-B can be examined at a 7168-fold dilution of the antibodies; the B3-type RBCs were examined using a 2560-fold dilution. The more apparently distinction has been concluded. In addition, the dilution for B3-type was 20-times higher than the agglutination method (128) indicating a much more precise determination of subtyping. The results for B and B3 types in Table 2-4 are summarized in Fig. 5 to 
illustrate the dilution fold differences, showing that there is a much greater apparent variation with the detaching method than the agglutination method, meaning that there is less risk of misidentifying B3 as 0 type.

Table 4. Optical detaching tests with serial antibody dilutions and the associated laser powers ${ }^{d}$

B-type RBC on anti-B surface

B3-type RBC on anti-B surface

Fold dilution of antibody Power (mW) Interaction Fold dilution of antibody Power (mW) Interaction

\begin{tabular}{cccccc}
5120 & 145 & $\square$ & 2560 & 5 & $\square$ \\
\hline 6144 & 10 & $\square$ & 3072 & 4 & $\square$ \\
7168 & 5 & $\square$ & & \\
\hline 8192 & 4 & $\square$ & &
\end{tabular}

प: RBC attached; $\square:$ RBC detached

\subsection{Quantitative analysis}

First, the B-type RBCs data in Table 4 was quantitatively analyzed and illustrated in Fig. 6, showing that the antibody dilution $(D)$ is inversely proportional to the laser power $(P)$. The R-squares is 0.98 , validating the experiment results. For confirming the reliability, we performed the extra experiment with identical procedures (dilution folds: 1 to 8194) for A-type RBCs, and gained the exactly same results with B-type case.

For evaluating the antigen expression on the RBCs, the maximum dilution of antibody in B-type tests is 2.8 times (7168/2560) the B3-type was found, meaning that the antigen expression on the B3-type RBC is $35.7 \%(1 / 2.8)$ of the B-type RBC. The result is consistent with the literatures $[11,12]$ using similar RBC types. Thus, the quantitative analysis verified that the proposed methodology can precisely measure the bonding strength between the RBC and antibody-coated surface, as well as to detect the surface antigen expression on the RBC.

\section{Conclusion}

An alternative methodology was developed using the optical cell-detachment technique to detect the surface antigen expression on RBCs. The RBC subtyping demonstration has verified the proposed detection principle. The detection sensitivity was 20 -times higher than the agglutination method for 
determining B3-type RBC. A relatively small blood sample is required to detect RBC surface antigen expression with extremely high sensitivity, and also the subtype RBC can be distinguished without ambiguity. This study provides an alternative approach to analyze whole-cell-based antibody-antigen interactions. We believe the simple and intuitive methodology could be widely applicable and capable of automatic detection with broad potential in routine procedures.

\section{Declarations}

Acknowledgments: We thank Dr. HC Wang from the Dr. Lee Woman Clinic (Taipei, Taiwan) for providing professional opinions to help us refine this manuscript.

Funding: The study was funded by the Ministry of Science and Technology (NSC 101-2221-E-166-003 and NSC 102-2221-E-166-006).

Competing interests: The authors declare no competing interests.

\section{References}

1. Varady G, Cserepes J, Németh A, Szabó E, Sarkadi B. Cell surface membrane proteins as personalized biomarkers: Where we stand and where we are headed. Biomark Med 2013;7:803-19.

2. Fukuda, M. Cell surface glycoconjugates as onco-differentiation markers in hematopoietic cells. Biochim. Biophys. Acta 1985, 780, 119-150.

3. Banuls, M.P., A. Alvarez, I. Ferrero, A. Zapata, and C. Ardavin. Cell-surface marker analysis of rat thymic dendritic cells. Immunology. 79:298-304.

4. Takaishi S, Okumura T, Tu S, et al. Identification of gastric cancer stem cells using the cell surface marker CD44. Stem Cells 2009;27: 1006-20.

5. Springer T.A. Adhesion receptors of the immune system. Nature.1990; 346: 425-434.

6. Sleeman J.P.; Kim U.; LePendu J.; Howells N.; Coquerelle T.; Ponta H.; Herrlich P. Inhibition of MT-450 rat mammary tumour growth by antibodies recognising subtypes of blood group antigen $\mathrm{B}$. Oncogene 1999, 18, 4485-4494.

7. Nakagoe T.; Nanashima A.; Sawai T.; Tuji T.; Ohbatake M.; Jibiki M.; Yamaguchi H.; Yasutake T.; Ayabe H.; Matuo T. Expression of blood group antigens $\mathrm{A} ; \mathrm{B}$ and $\mathrm{H}$ in carcinoma tissue correlates with a poor prognosis for colorectal cancer patients. J Cancer Res Clin Oncol 2000, 126, 375-382.

8. Moldvay J.; Scheid P.; Wild P.; Nabil K.; Siat J.; Borrelly J.; Marie B.; Farré G.; Labib T.; Pottier G. Predictive survival markers in patients with surgically resected non-small cell lung carcinoma. Clin Cancer Res. 2000, 6, 1125-1134.

9. Olsson M.L., Clausen H. Modifying the red cell surface: towards an ABO-universal blood supply. $\mathrm{Br} \mathrm{J}$ Haematol. 2008;140(1):3-12.

10. Cartron, J.P.; Gerbal, A.; Hughes-Jones, C.; Salmon, C. 'Weak A' phenotypes: relationship between red cell agglutinability and antigen site density. Immunology 1974, 27, 723-727. 
11. Cho, D.; Shin, D.J.; Yazer, M.H.; Ihm, C.H.; Hur, Y.M.; Kee, S.J.; Kim, S.H.; Shin, M.G.; Shin, J.H.; Suh, S.P.; Ryang, D.W. The M142T mutation causes B3 phenotype: three cases and an in vitro expression study. Korean J Lab Med. 2010, 30, 65-9.

12. Chen, D.P.; Tseng, C.P.; Wang, W.T.; Sun, C.F. Genetic and mechanistic evaluation for the mixed-field agglutination in B3 blood type with IVS3+5G. A ABO gene mutation. PLoS One 2012, 7, e37272.

13. Mori, T.; Katayama, Y. Signal amplification in flow cytometry for cell surface antigen analysis. J. Biochem. 2019, 166, 205-212.

14. Arunachalam, B.; Talwar, G.P.; Raghupathy, R. A simplified cellular ELISA (CELISA) for the detection of antibodies reacting with cell-surface antigens. J. Immunol. Methods. 1990, 135:181-189.

15. Efros, R.B.; Zeller, E.; Dillard, L.; Walford, R.L. Detection of antibodies to cell surface antigens by a simplified cellular ELISA (CELISA). Tissue Antigens, 1985, 25:204-211.

16. Neuman, K.C. et al. Single-molecule force spectroscopy: optical tweezers, magnetic tweezers and atomic force microscopy. Nat Methods 2008, 5, 491-505.

17. Zhu, R.; Avsievich, T.; Popov, A.; Meglinski, Cells 2002, 9, 545.

18. Svoboda, K.; Block, S.M. Force and velocity measured for single kinesin molecules. Cell 1994, 77, 773-784.

19. Ros, R. et al. Antigen binding forces of individually addressed single-chain Fv antibody molecules. Proc. Natl. Acad. Sci. USA 1998, 95(13), 7402-7405.

20. Lin, S. et al. Force measurement of specific antibody-antigen interactions in pH-varied liquid environments. Proc. of IEEE on Emerging Inf. Technol. Conference 2005 Aug., 15-16.

21. Uchihashi, T. et al. Functional extension of high-speed AFM for wider biological applications. Ultramicroscopy 2016, 160, 182-196.

22. Ashkin, A.; Dziedzic, J.M. Optical trapping and manipulation of single living cells using infra-red laser beams. Berichte der Bunsengesellschaft für physikalische Chemie 1989, 93, 254-260.

23. Mammen, M.; Helmerson, K.; Kishore, R.; Choi, S.K.; Phillips, W.D.; Whitesides, G.M. Optically controlled collisions of biological objects to evaluate potent polyvalent inhibitors of virus-cell adhesion. Chemistry \& Biology 1996, 3, 757-763.

24. Qian, X.; Holmlin, R.E.; Whitesides, G.M.; Chen, C.Y.; Schiavoni, M.; Smith, S.P.; Assi, F.; Prentiss, M.G. Measuring the inhibition of adhesion of lectins to the surface of erythrocytes with optically controlled collisions between microspheres and erythrocytes. The Journal of Physical Chemistry B 2002, 106, 9159-9164.

25. Moffitt, J.R.; Chemla, Y.R.; Smith, S.B.; Bustamante, C. Recent advances in optical tweezers. Annu. Rev. Biochem 2008, 77, 205-228.

26. Yang, B.W.; Mu, Y.H.; Huang, K.T.; Li, Z.; Wu, J.L.; Lin, Y.A. The evaluation of interaction between red blood cells in blood coagulation by optical tweezers. Blood Coagulation \& Fibrinolysis 2010, 21, 505-510. 
27. Crick, A.J.; Theron, M.; Tiffert, T.; Lew, V.L.; Cicuta, P.; Rayner, J.C. Quantitation of malaria parasiteerythrocyte cell-cell interactions using optical tweezers. Biophysical Journal 2014, 107, 846-853.

28. Priezzheva, A.; Lee, K. Potentialities of laser trapping and manipulation of blood cells in hemorheologic research. Clinical Hemorheology and Microcirculation 2016, 64, 587-592.

29. Lee, K.; Kinnunen, M.; Khokhlova, M.D.; Lyubin, E.V.; Priezzhev, A.V.; Meglinski, I.; Fedyanin, A.A. Optical tweezers study of red blood cell aggregation and disaggregation in plasma and protein solutions. Journal of Biomedical Optics 2016, 21(3), 035001.

30. Chen, K.Y.; Lin, T.H.; Yang, C.Y.; Kuo, Y.W.; Lei, U. Mechanics for the adhesion and aggregation of red blood cells on chitosan. Journal of Mechanics 2018, 34, 725-732.

31. Lee, K.; Shirshin, E.; Rovnyagina, N.; Yaya, F.; Boujja, Z.; Priezzhev, A.; Wagner, C. Dextran adsorption onto red blood cells revisited: single cell quantification by laser tweezers combined with microfluidics. Biomedical Optics Express 2018, 9(6), 2577-2764.

32. Agrawal, R.; Smart, T.; Nobre-Cardoso, J.; Richards, C.; Bhatnagar, R.; Tufail, A.; Shima, D.; H. Jones, P.; Pavesio, C. Assessment of red blood cell deformability in type 2 diabetes mellitus and diabetic retinopathy by dual optical tweezers stretching technique. Sci. Rep. 2016, 6, 15873.

33. Lin, C.L.; Pan, M.J.; Chen, H.W.; Lin, C.K.; L, C.F.; Baldeck, L.P. Laser cross-linking protein captures for living cells on a biochip. In Frontiers in Biological Detection: From Nanosensors to Systems VII 2015 March; 9310, 93100D; International Society for Optics and Photonics.

34. Lin, C.F.; Lin, C.K.; Liu, Y.J.; Chiang, C.H.; Pan, M.J.; Baldeck, L.P.; Lin, C.L. Laser-induced cross-linking GFP-AcmA' bioprobe for screening Gram-positive bacteria on a biochip. RCS Advances 2014, 4, 62882-62887.

35. Chen, J.W.; Lin, C.F.; Wang, S.G.; Lee, Y.C.; Chiang, C.H.; Huang, M.H.; Lee, Y.H.; Vitrant, G.; Pan, M.J.; Lee, H.M.; Liu, Y.J.; Baldeck, P.L.; Lin, C.L. New biodiagnostics based on optical tweezers typing red blood cells; and identification of drug resistant bacteria. In Optical Trapping and Optical Micromanipulation X 2013 September; 8810, 88101N; International Society for Optics and Photonics.

36. Mazia, D.; Schatten, G.; Sale, W. Adhesion of cells to surfaces coated with polylysine. Applications to electron microscopy. The Journal of Cell Biology 1975, 66, 198-200.

37. Huang, W.M.; Gibson, S.J.; Facer, P.G.U.J.; Gu, J.; Polak, J.M. Improved section adhesion for immunocytochemistry using high molecular weight polymers of L-lysine as a slide coating. Histochemistry 1983,77, 275-279.

38. Seurynck-Servoss, S.L.; White, A.M.; Baird, C.L.; Rodland, K.D.; Zangar, R.C. Evaluation of surface chemistries for antibody microarrays. Analytical Biochemistry 2007, 371, 105-115.

39. Ashkin, A. Forces of a single-beam gradient laser trap on a dielectric sphere in the ray optics regime. Biophys. J. 1992, 61, 569-582.

40. Wright, W.H.; Sonek, G.J.; Berns, M.W. Parametric study of the forces on microspheres held by optical tweezers. Appl. Opt. 1994, 33, 1735-1748.

41. Singer, W.; Bernet, S.; Hecker, N.; Ritsch-Marte, M. Three-dimensional force calibration of optical tweezers. J. Mod. Opt. 2000, 47, 2921-2931. 
42. Grier, D.G. A revolution in optical manipulation. Nature $2003,424,810-816$.

\section{Figures}

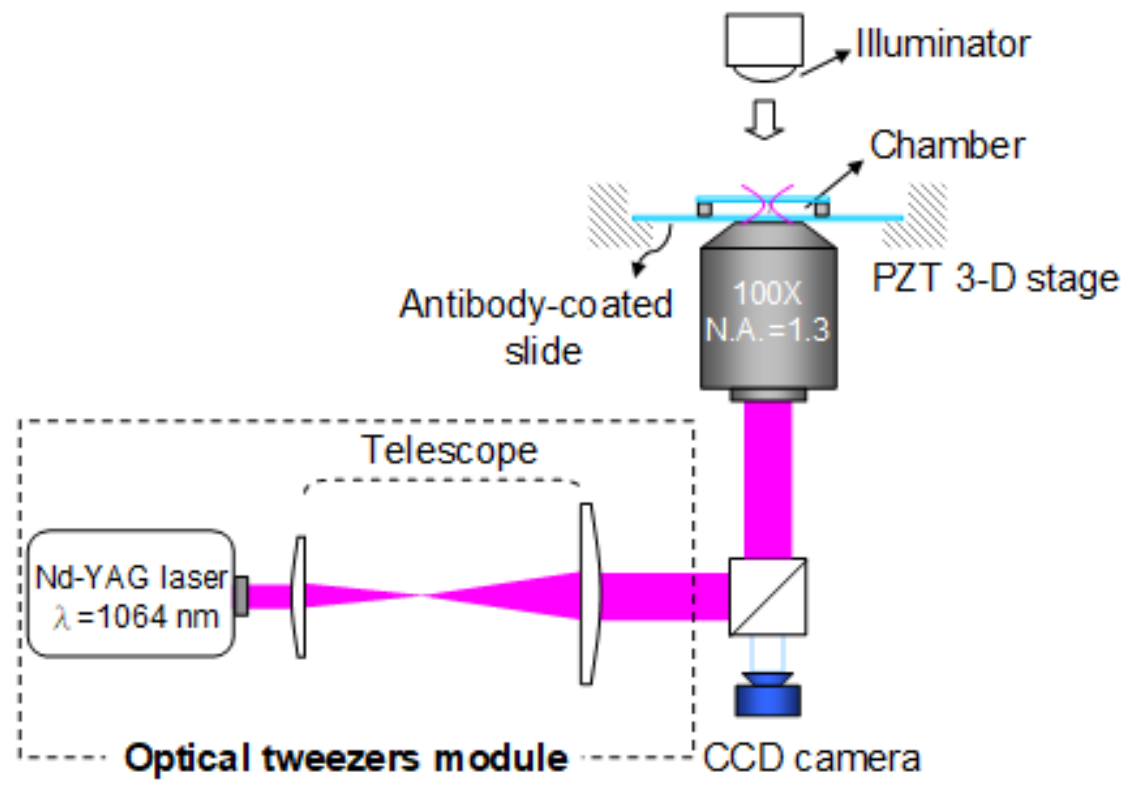

\section{Figure 1}

Optical tweezers experimental setup: a schematic figure of optical tweezers and the detail (not in scale) of the sample chamber.

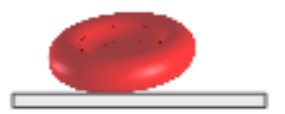

(a) Optical tweezers tums off

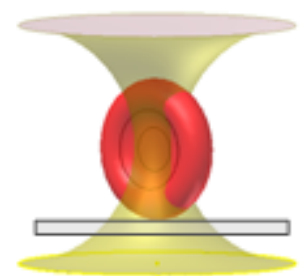

(b) Optical tweezers turn on

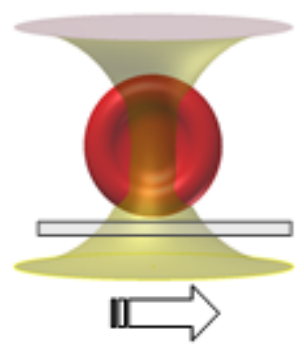

(c) Dragging speed $=5 \mu \mathrm{m} / \mathrm{sec}$; power $\geqq$ threshold

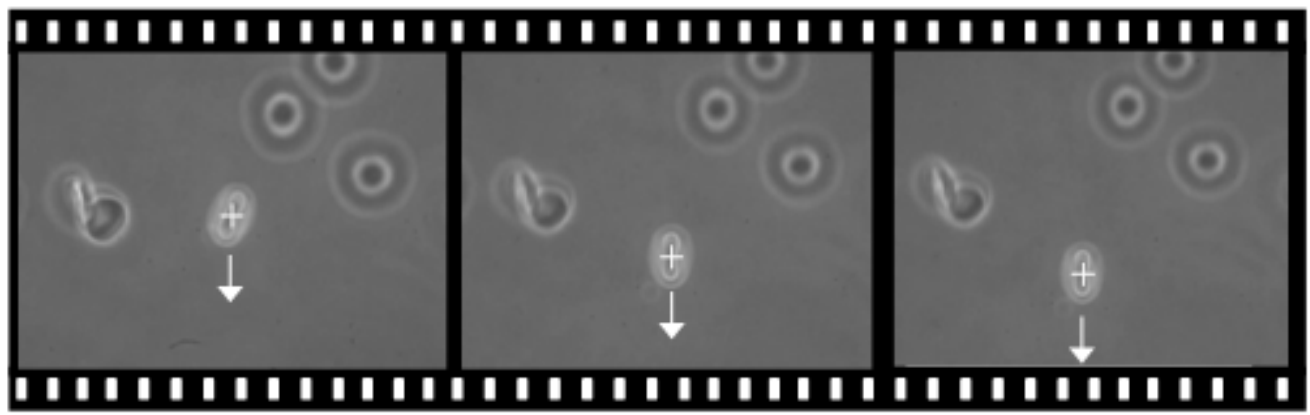

0 second

1 second

1.5 second

(d) $\mathrm{RBC}$ is dragged using optical tweezers. 


\section{Figure 2}

Schematic illustration (not in scale) of an RBC trapped by optical tweezers on a non-specific antibodyantigen interaction surface: (a) RBC on the surface before the optical tweezers is turned on; (b) RBC stands up after the optical tweezers is turned on; (c) the suspended RBC is dragged by the optical tweezers; (d) the manipulation films (Visualization 1): the cross is the position of the optical tweezers trapping spot; the arrow presents the dragging direction of the optical tweezers.

(a) Detail of the RBC stuck on the antibody coating surface
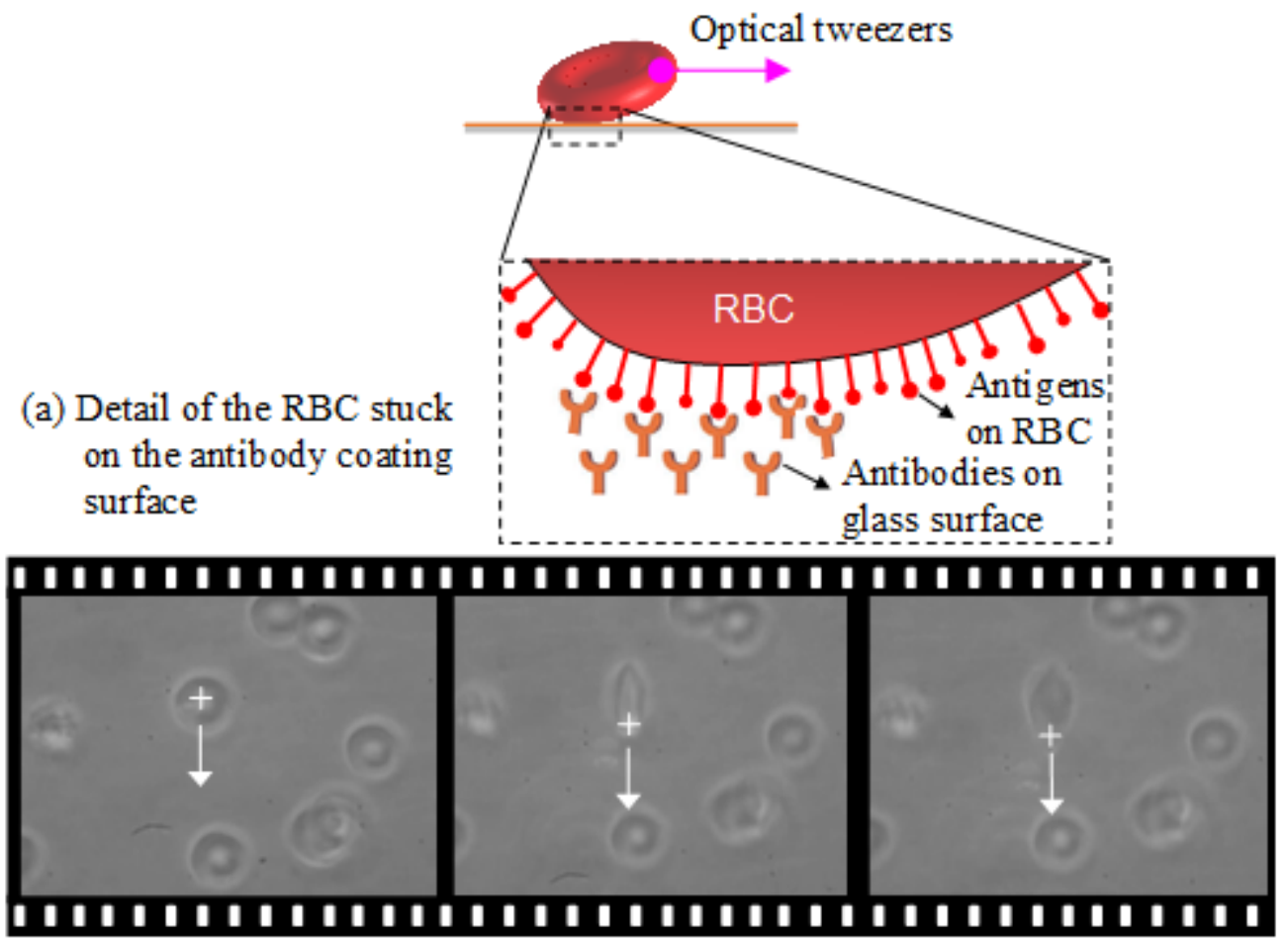

0 second 1 second

1.5 second

(b) RBC is stretched by optical tweezers

Figure 3

(a) Schematic illustration (not in scale) detailing RBC attachment to the antibody-coated surface. (b) RBC is stretched by optical tweezers but still attached to the anti-A-coated surface (Visualization 2). 
Antibody coating

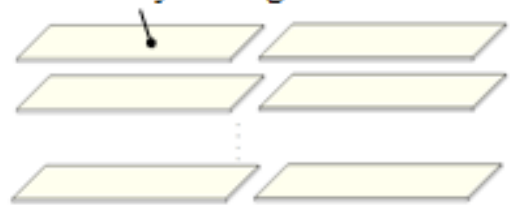

Dilution folds of antibody:

$1,2,4,8, \ldots, 1024,2048,2560,3072 \ldots$.

(a)

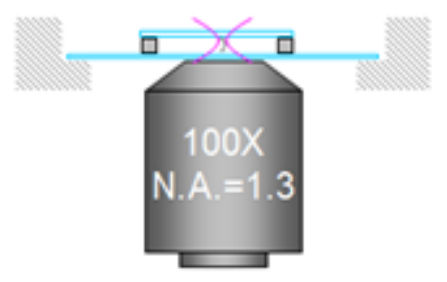

(c)

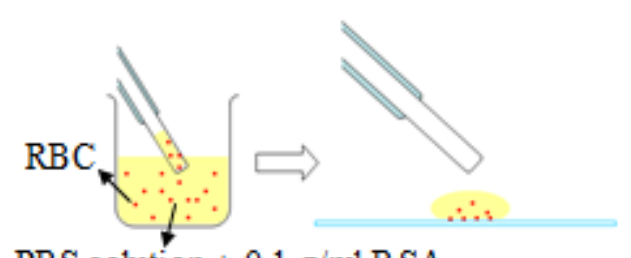

PBS solution $+0.1 \mathrm{~g} / \mathrm{ml} \mathrm{BSA}$

(b)

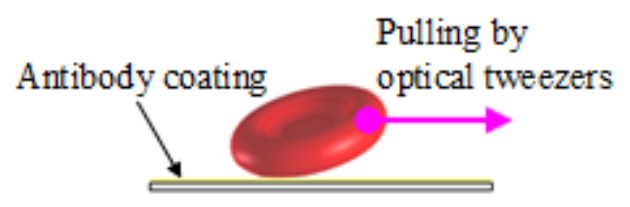

(d)

\section{Figure 4}

Steps of optical cell-detachment (not in scale): (a) prepare the antibody-coated slides using serial dilutions, then storage at $4^{\circ} \mathrm{C}$; (b) one drop blood sample incubated on the selected antibody-coated slide; (c) package the sample specimen, then place on the optical tweezers stage; (d) identify an attached RBC, and then try to horizontally detach the RBC using the optical tweezers at a moving speed of $5 \mu \mathrm{m} / \mathrm{sec}$, and repeat 10 times with at least 5 RBCs

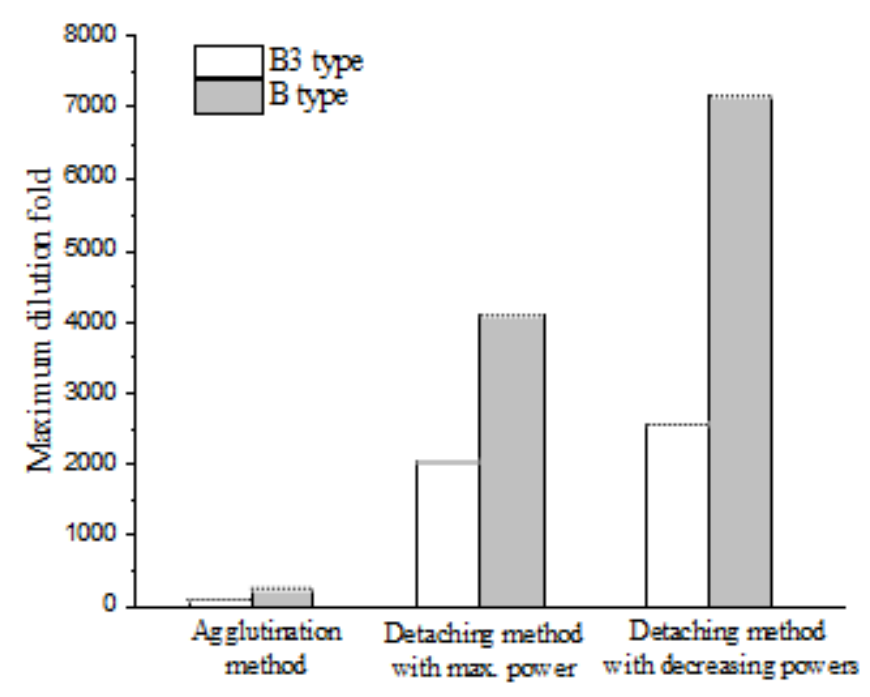

\section{Figure 5}

Comparison of the maximum fold dilution according to the different detection methods for RBC subtyping 


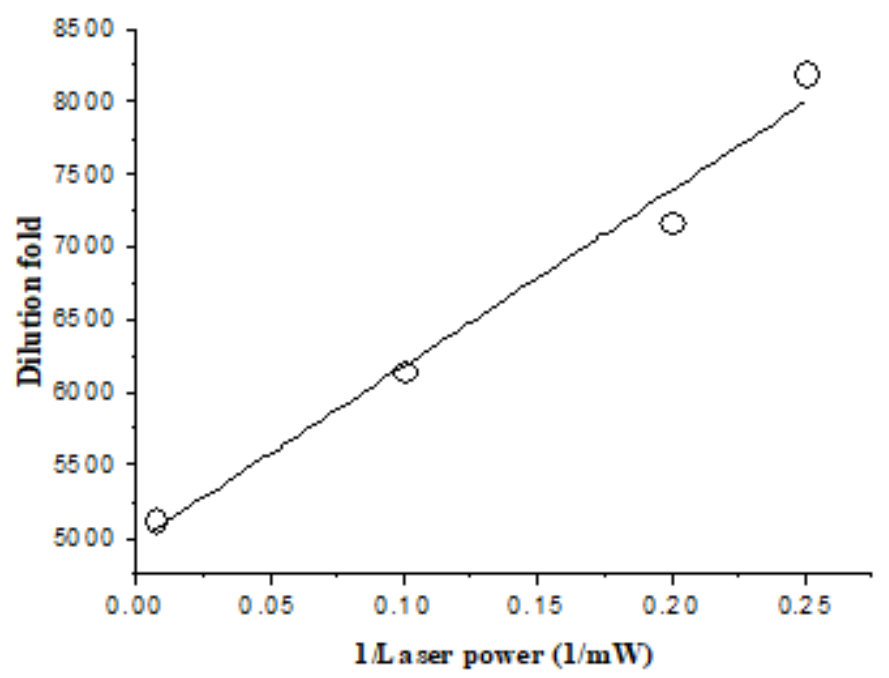

Figure 6

The relationship between fold dilution and 1 /laser power 